\title{
SOMOS HERDEIROS DO PECADO ORIGINAL? ALGUMAS CONSIDERAÇÕES ACERCA DOS DISCURSOS RELIGIOSOS PERANTE AO CORPO NA ANTIGUIDADE TARDIA
}

\author{
ARE WE HEIRS OF ORIGINAL SIN? SOME CONSIDERATIONS \\ ABOUT THE RELIGIOUS SPEECHES BEFORE THE BODY IN LATE \\ ANTIQUITY
}

Pablo Gatt ${ }^{30}$

\begin{abstract}
The present article aims to analyze representations about the body in Roman and medieval society according to the discourses that were propagated by the representatives of the Christian religion of the first centuries and the currents opposed to Christianity. In this sense, we will discuss how the body was seen in Late Antiquity as well as in the Middle Ages, since with the advent of the Original Sin it was renounced to the social margin and depreciated under the aspect of the concupiscence of the flesh. In addition, we will investigate in the imaginary of each society how the body was connected to the social scope and its function in the institution of the marriage.

\section{RESUMO}

O presente artigo tem como objetivo analisar as representações acerca do corpo na sociedade romana e no medievo de acordo com os discursos que eram propagados pelos representantes da religião cristã dos primeiros séculos e pelas correntes opostas ao Cristianismo. Nesse sentido, discutiremos como era visto o corpo na Antiguidade Tardia assim como na Idade Média, uma vez que com o advento do Pecado Original o mesmo passou a ser renegado à margem social e depreciado sob o aspecto pelo viés da concupiscência da carne. Ademais, investigaremos no imaginário de cada sociedade como o corpo estivera ligado ao âmbito social e a sua função na instituição do casamento.
\end{abstract}

\section{KEYWORDS}

Body; Imaginary; Speech

\section{PALAVRAS-CHAVE}

Corpo; Imaginário; Discurso

\section{Introdução}

Jacques Le Goff considera que de todas as grandes revoluções culturais que ocorrem no Ocidente, das quais foram promovidas pelo Cristianismo, a que está ligada ao corpo fora uma das principais (LE GOFF, 1994, p. 145), uma vez que no século V, a Igreja Cristã já se destacava no antigo mundo romano como uma Instituição Central. O enfoque

\footnotetext{
${ }^{30}$ Doutorando em História Medieval, Universidade Federal do Espírito Santo: gattpablo@ gmail.com
} 
antes positivo dado à natureza humana, tal como a musculatura dos corpos dos soldados, com a presença do Cristianismo concede lugar as questões da vontade do ser, dos desejos corporais. A influência e preocupação provinda da doutrina pessimista de Agostinho de Hipona em relação ao corpo espelha e conduz nos discursos religiosos uma negação da concupiscência da carne, em que a vontade primeira do corpo como instrumento de pecado ascende ao primeiro plano.

Nesse sentido, a carne do corpo humano no início da Idade Média oscila entre o Pecado Original de Adão e Eva e a salvação do sujeito cristão (BROWN, 1990, p. 357). É uma história cristã de renúncia sexual, visto que no ano de 546 o imperador Justiano proíbe os atores em suas peças teatrais de vestirem os mantos sagrados dos monges. É o início do trato rigoroso do Cristianismo quanto ao corpo que, pautado pela desobediência original, deferiu nas cidades e aldeias paulatinamente um imaginário homogêneo.

\section{O discurso do corporal na Antiguidade Tardia}

Embora no seio da Igreja dos primeiros séculos houvesse controvérsias perante os sentidos que carregavam a carne, diferentemente era o imaginário do homem da Roma antiga, em que a única preocupação e negação institucional permeava a passividade do cidadão aristocrata.

Por meio dessas palavras, estabelece aquilo que lhe parece como a "ordem natural": a função sexual ativa do homem aristocrático e cidadão, compatível com o seu autodomínio, integridade física, controle e domínio sobre os demais membros da sociedade e povos: mulheres, libertos e escravos. A sua virilidade estaria representada em seu ativo papel sexual e social (FEITOSA, 2008, p. 132).

Do mesmo modo, no Império do Oriente e anteriormente ao apogeu do Cristianismo encontramos uma moral em que o dinheiro e o estamento social se sobressaem ao Evangelho no que concerne o casamento e o divórcio. Entretanto, a lógica cristã gradualmente transforma o corpo em um templo sacrossanto (BROWN, 1990, p. 360), na união dos sexos pela oposição homem e mulher, em que ambos deveriam gerar filhos para a perpetuação da palavra de Deus. O pai de família, no século IV, perde o direito de negar o 
filho, assim como são proibidos os métodos anticonceptivos, uma vez que tais atitudes são movidas às esferas pagãs.

O papel de Deus aparece na constituição do casal e posteriormente na formação dos filhos, engendrando uma sociedade de lares devotos, de sujeitos cristãos, acompanhados de restrições às práticas sexuais, pois para que os homens assumissem a forma de Cristo ressuscitado era necessário a renúncia do corpo. Dado que os líderes latinos atrelavam o mal presente no mundo à vontade humana, os Padres do deserto defendiam o ideal da castidade como forma de abundância e de paz. É, então, no século VI, que as noções cristãs se tornam hegemônicas no imaginário desses homens, visto que "da Antiguidade ao cristianismo, passa-se de uma moral que era essencialmente uma busca de uma ética pessoal, a uma moral como obediência a um sistema de regras.” (FOUCAULT, 2006, p. 289-290). No medievo a representação do ato sexual, quando praticado em dias proibidos pela Igreja, causava a geração de filhos leprosos e epiléticos. Nesse sentido, o "desbaratamento do corpo marcou o término do mundo clássico e o início da Idade Média." (BROWN, 1990, p. 363), dando início a um período de uma moral em que há a valorização da renúncia de si.

Por sexualidade entendemos um dispositivo que engloba os interdiscursos, atitudes mentais, proposições filosófica, morais e elementos heterogêneos. Empregada como nomenclatura somente no século XIX, para descrever a historicidade dos corpos e das práticas sexuais, na Idade Média a sexualidade fora um peccatum, um desvio da justiça original, um peso carregado pela humanidade devido ao Pecado Original, pois "o cristianismo produziu uma nova orientação para a sexualidade, introduzindo a ideia que há uma relação entre carne e pecado." (JARDIM, 2006, p.125). Nota-se que a sexualidade é colocada como um valor singular constituído por cada grupo social no tempo e espaço, variando de acordo com cada sociedade analisada e imaginário, artificio construído socialmente e usado nos interdiscursos religiosos da Idade Média para o controle dos corpos.

Michel Foucault procurou realizar nos anos 80, através de uma análise discursiva, a genealogia da sexualidade e a identificação da construção de um sujeito desejante, dado ao apogeu dos estudos voltados à prática do poder nos anos 70. Em sua obra Microfísica do poder de 1979, Foucault acredita que o sistema de poder e as práticas corporais estão diretamente ligadas. Nesse sentido, a prática do poder não impede o saber sobre determinado 
assunto, na verdade, esse poder produz o saber, constituindo uma verdade acerca do corpo, em que por meio dos canais discursivos ocorre a produção de discursos com efeitos de verdade.

Em qualquer sociedade encontramos múltiplas relações de poder que atravessam o corpo social, todas ligadas à prática do discurso, posto que esse poder está interiorizado na consciência das pessoas e nas relações que submetem inquéritos de verdades, assim como foram submetidos os homens medievais às pastorais de confissões. A analogia de que Cristo era a cabeça da Igreja, $(E f-5,23)$, fizera do Alto Clero latino uma poderosa Instituição espiritual e dominante no período medieval. Nessa perspectiva, o Clero desenvolveu um sistema de representações ao qual o mesmo estaria ligado a alma enquanto a maior parte da população, a laicidade, estaria ligada ao corpo. Esse discurso clerical consequentemente versaria o ideal da superioridade e uma hierarquia dos membros do Clero perante o popular (RANHEL, 2018, p. 16). Essa associação do Clero com a alma fizera com que a sociedade fosse guiada pelos mesmos em busca da salvação eterna, na ideia de que o corpo só seria salvo se seguisse as vontades da alma. Portanto, uma vez que submetidos ao poder das pastorais de confissões mediante ao discurso religioso o homem estaria no caminho correto da salvação, em que somente a Igreja encarnada nos valores espirituais no mundo poderia conduzir os homens na salvação das almas.

Esse poder que sobrepuja as regras e circula em cadeias funcionou como uma rede, ultrapassando e moldando o homem ao impor aparelhos de punição, ao sujeitar seus corpos, gestos, comportamentos e atitudes. Por isso, estudar a representação do homem medieval é compreender o social, a cultura, o religioso e as influências que marcaram o interdiscurso do período.

A desmistificação da liberdade sexual existente na Roma antiga e a quebra do pensamento de que foi o Cristianismo o promotor de uma moral sexual reguladora foram ideias cunhadas pelo historiador francês Paul Veyne. Em sua obra Sexo e poder em Roma, publicada originalmente em 2005, o historiador elucida que temas como castidade, finalidade reprodutiva e contenção já se faziam presente cem anos antes do advento do Cristianismo, quando na Roma antiga prevaleceu-se uma conduta sexual de ordem cívica, em que no corpo do homem refletiam seus deveres como cidadão. Michel Foucault em $O$ cuidado de si de 
1984, compartilha de uma visão similar à de Veyne, ao elaborar uma análise do corpo a partir da medicina grega, entre a necessidade de um domínio sobre os desejos e de uma luta contra o prazer, em que será encontrada mais tarde na moral discursiva cristã.

O sexo era visto pela igreja como um mal necessário, indispensável para que a humanidade pudesse cumprir a orientação bíblica que propõe aos homens e mulheres serem fecundos, de modo a multiplicar e encher a terra de sua espécie, conforme se lê em Gênesis (Cap. 1, v. 28). Entretanto, isto desvirtuava o ser de sua verdadeira vocação que requer um total controle sobre os desejos da carne, sobretudo, a abstinência sexual. (JARDIM, 2006, p. 126)

Durante toda a história da era cristã não encontramos um modelo comportamental homogêneo no que tange a sexualidade a ser seguido. Na Roma antiga a promiscuidade estava atrelada aos escravos, que computavam $25 \%$ da população, uma vez que não eram considerados cidadãos pois não tinham deveres morais algum com o Império. Nesta lógica, o casamento funcionava como um negócio, em que não se fazia presente o sentimento a dois. Casar-se era um dever cívico, visto que o único objetivo era o de procriação, gerando homens livres para o Império. A instituição do casamento monogâmico já se fazia presente, nesse sentido, existiu uma conduta ordem cívica e de responsabilidade para com a sociedade. O sexo não deveria ser praticado livremente, mas sim com o intuito da reprodução, embora encontremos práticas contrárias ao discurso esperado, uma vez que o cidadão aristocrata poderia procurar a satisfação dos prazeres com um escravo ou em lugares públicos próprios para o flerte, na condição de que o mesmo jamais poderia ser submisso.

A virilidade, significando uma soberania sobre si, é uma virtude do cidadão. Esse homem viril era considerado um "soldado do dever cívico", um ser moralmente responsável. Esse homem romano tinha uma série de tarefas a realizar: o ofício da guerra, a escrever leis, a manutenção e preservação da gens. Ser, portanto, viril, era tido como útil para que o exercício dessas atividades, e por conta disso a carência de virilidade não era vista com bons olhos. Ser efeminado, não ser viril, era trair o mos maiurum. Este ideal romano expressava, além da questão do domínio de si, o domínio exercido na vida pública. Ser senhor de si e, mais ainda, ser viril era uma qualidade muito desejada. (MENNETTI, 2011, p. 45-46) 
Uma vez que estamos falando de homens livres da aristocracia, ser penetrado ou submisso é malvisto, o cidadão romano deve sempre ser ativo, pois o seu papel sexual reflete no corpo social. Em suma, em um primeiro momento da história romana, o corpo esteve atrelado a um dever cívico, em que a figura masculina deveria zelar pelo lar, proprietário de sua esposa, filhos e bens, compreendendo uma sociedade de valores estéticos.

No final da fase do Império, a filosofia estoica abarcou a vida privada desses sujeitos. Descolando de uma conduta vinculada à cidade para o equilíbrio pessoal, o homem passou a transitar entre a vigilância no que tange o prazer e a real necessidade da matéria. $\mathrm{O}$ corpo passou a se enquadrar entre a dualidade da contenção e da educação, entretanto, jamais da satisfação dos desejos. Nesta ocasião, fundou-se uma luta no interior do homem frente aos excessos provocados pelo prazer. Mesmo com a virada estoica o sexo ainda continuou a ser visto para a procriação, visto que "quem quer ser um homem de bem só deve fazer amor para ter filhos. O estado de casamento não serve aos prazeres venéreos.” (VEYNE, 2009, p. 47).

O cidadão romano orientou-se para os conflitos internos que necessitam ser resolvidos, mesmo que ainda responsável pelo lar, a mulher agora é sua companheira e não propriedade, única em sua vida. Contudo, o sexo ainda está envolto por uma série de observâncias, dado que a necessidade de exame de si esteve voltada para o pessoal e não mais ao cívico, em que o ser ativo do mesmo modo poderá cair na tentação e nos excessos do prazer. Aqui a prática do ato sexual por intermédio da realização do prazer é vista como igual ao praticado com uma amante ou com meretrizes. Formulou-se uma conduta voltada para a procriação e não para os afetos e caricias, em que concomitantemente o casamento passou a abranger uma visibilidade social, não mais realizado apenas no interior das elites, na medida em que agora qualquer desvio conjugal transparece na comunidade.

O estoicismo, de fato, fora uma filosofia que estimulou a autonomia e o controle de si. Nessa perspectiva, o sexo é vigiado pelo homem no que tange o seu prazer, sempre observando a não exaltação da carne, pautado em um autocontrole. Temos então um mundo pagão dividido em dois momentos, em que questões voltadas ao tema da moral sexual já se faziam presentes. Encontramos um primeiro momento abarcado pela conduta do dever cívico, posto que o casamento e o ato sexual refletem a estrutura da sociedade romana, visto que o homem é obediente ao Império. Ademais, nos deparamos com um segundo momento 
e a afirmação da contenção do eu, em que na filosofia estoica o homem é praticante do autocontrole e vigilante do prazer interno.

O que estava em jogo era uma mudança sutil na percepção do próprio corpo. Os homens e mulheres dos séculos subsequentes não apenas foram cercados por um conjunto diferente e mais rigoroso de proibições. Passaram também a ver seus próprios corpos sob um prisma diferente. Vista através da lente do cristianismo plenamente elaborado do início da Idade Média, a imagem do corpo das pessoas do século II parecia estranhamente indistinta. Ela era turvada por uma sensualidade difusa. (BROWN, 1990, p. 35)

\section{Os primeiros discursos cristãos de negação corporal}

Embora a comunidade cristã durante os primeiros séculos tenha sido diversificada no que diz respeito à moral sexual, citamos alguns de autores cristãos e seus pareceres acerca do assunto, uma vez que muitos cristãos usaram o corpo como mecanismo demonstrativo da fé, seja pela castidade, clausura ou renúncia de todos os bens materiais. Posto que no mundo pagão a pregação de uma conduta sexual se restringia perante ao estamento do indivíduo, no Cristianismo temos um código moral propagado a toda comunidade, independente da região, raça ou estamento.

Durante os primeiros séculos da era cristã, o apologista cristão grego Clemente de Alexandria (215), pregou um "ideal humano da continência, ou seja, o que é estabelecido pelos filósofos gregos, ensina-nos a resistia à paixão, para que não nos tornemos subservientes a ela, e a treinar os instintos para que busquem metas racionais." (Clemente de Alexandria, apud BROWN, 1990, p. 36). Para Clemente de Alexandria o prazer sexual é errôneo, entretanto a relação sexual, desde que praticada para o fim reprodutivo, deveria promover a renovação da carne frágil, em que homem é vigilante desse prazer e seu próprio juiz.

Diferentemente em Cartago, província romana da África, o apologista cristão Tertuliano (220), defendeu uma moral sexual mais rigorosa. O autor cristão promoveu uma doutrina pautada na suspensão da atividade sexual, uma vez que o desejo sexual se faz presente na vida do homem e é incapaz de ser apagado seja pelo batismo ou pela renúncia, posto que a atividade sexual instiga o pecado. Tertuliano também pregava o exame dos 
desejos e a vigilância quase que contínua da carne, pois o desejo sexual representa a marca do pecado e rompendo-se com o desejo, rompe-se com o pecado. É levar uma vida sob o exame constante de si.

Especula-se que com o movimento filosófico do gnosticismo no segundo século, com Valentim (160), ocorreu a promoção de um estigma negativo ao corpo. Para o gnóstico, o corpo fora um acidente e estranho ao verdadeiro eu. Nessa mesma perspectiva negativa, Cipriano de Cartago (258), no século III, que teve Ambrósio de Milão (397), e Agostinho de Hipona (437), como seus sucessores, considera a carne dos cristãos como um sinal constante da luta contra as maldades do mundo. Ambrósio, no século IV, também acolhe a visão da carne como um sinal eminente do perigo, posto que é sexualizada. Segundo a filosofia do maniqueísmo, o ato sexual, mesmo que praticado para a reprodução, contribuía para o alargamento das forças do mal, assim como fora defendido por Gregório de Nissa (394), e Jerônimo (420), visto que a sexualidade fora a responsável pela queda original. Nesse sentido, os dirigentes da Igreja Latina repeliram o casamento para longe do sagrado, construindo um aparato discursivo de negação a qualquer ato sexual. (BROWN, 1990, p. 111).

No final do século IV, como um dos principais representantes do Cristianismo dos primeiros séculos, Agostinho irá se dedicar à escrita da doutrina cristã ao optar pela vida ascética no pequeno mosteiro de Hipona. O apologista cristão em suas obras afirma que a sexualidade está presente nos homens, inclusive esteve presente em Adão e Eva de maneira consciente, dado que "as núpcias dignas da felicidade do Paraíso, se não tivesse havido o pecado, teriam gerado filhos dignos de amor e não teriam vergonha da volúpia (libido).” (CD, XIV, XXIII, tradução nossa) ${ }^{31}$. Vemos em Agostinho a aceitação do matrimônio desde que o intuito final seja a reprodução (CD, XIV, XXIV), entretanto, a castidade e a abstinência ainda são defendidas como os modos mais elevados de vida, pois "esta paixão libidinosa, de

\footnotetext{
${ }^{31}$ Ver no original: "Et ideo illae nuptiae dignae fehcitate paradisi, si peccatum non fuisset, et diligendam prolem gignerent et pudendam libidinem non haberent." (CD, XIV, XXIII).
} 
que agora estamos a tratar, excita a vergonha tanto mais quanto mais o espírito.” (CD, XIV, XXIII, tradução nossa) ${ }^{32}$.

Para Agostinho de Hipona a prática do ato sexual é entendida em função de um debitum conjugale, visto que a desobediência é compreendida como desejo sexual não controlado, uma vez que toda desobediência reflete a desobediência original perante ao criador. Temos um Agostinho preocupado com o desejo sexual, em que esse desejo deveria ser disciplinado e observado constantemente.

\begin{abstract}
Mas quando o comando da vontade retém os outros membros, sem os quais os excitados contra essa vontade pela paixão libidinosa não podem alcançar o que desejam, guarda-se a castidade e não desaparece, embora não permitido, o prazer do pecado. No Paraíso as núpcias não teriam esta oposição, esta repugnância, esta luta entre a vontade e a libido ou, pelo menos, esta deficiência da libido ao apelo da vontade, se a desobediência culpável não provocasse o castigo duma desobediência; esses membros obedeceriam, com o todos os outros, à vontade $(C D$, XIV, XXIII, tradução nossa $)^{33}$.
\end{abstract}

A construção do discurso de Agostinho caracteriza-se pela contrariedade ao ato sexual praticado pelo prazer, pois o Pecado Original de Adão e Eva acarretou para os homens a mancha do pecado, transferindo uma negatividade para a prática da atividade sexual, dado que "agora na sua carne é movido pela paixão libidinosa." (CD, XIV, XXIV, tradução nossa $)^{34}$.

Desde o Pecado Original, parece estar sendo construída uma estratégia de controle das sexualidades masculina e feminina, tal como diz o texto bíblico: "o teu desejo te impelirá ao teu marido e ele te dominará” (Gênese, Cap. 3, v.16). À desobediência dos homens à vontade de Deus, Ele nos puniu com a desobediência "daquela" parte do corpo dos homens à vontade desses. Doravante, homens e mulheres pagarão pelo pecado do orgulho,

\footnotetext{
${ }^{32}$ Ver no original: "Nunc vero pudet animum resisti sibi a corpore, quod ei natura inferiore subiectum est." (CD, XIV, XXIII).

${ }^{33}$ Ver no Original: "Sed cum alia membra retinentur voluntatis imperio, sine quibus illa, quae contra voluntatem libidine concitantur id qod appetunt implere noii possunt, pudicitia custoditur, non amissa, sed non permissa delectatione peccati. Hunc renisum, hanc repugnantiam, hanc voluntatis et libidinis rixam vel certe ad voluntatis sufficientiam libidinis indigentiam procul dubio, nisi culpabilis inoboedientia poenali inoboedientia plecteretur, in paradiso nuptiae non haberent, sed voluntati membra, ut cetera, ita cuncta servirent." (CD, XIV, XXIII).

${ }^{34}$ Ver no original: "ut in eius carne etiam illud non nisi eius voluntate moveretur, quod nunc nisi libidine non movetur.” (CD, XIV, XXIV).
} 
aquele que os impeliu à desobediência, com a incapacidade de governar os seus próprios corpos, a luxúria os levará a uma armadilha, da qual quase não há escapatória, o preço da salvação será a eterna vigilância e, não apenas sobre o corpo, mas, sobretudo, sobre o pensamento, pois é neste campo que o pecado se insinua e corrompe o corpo, fato que é recorrente no discurso eclesiástico. (JARDIM, 2006, p.126)

Os discursos dos apologistas cristãos dos primeiros séculos reforçaram a mancha pecaminosa que estará presente no imaginário e representações dos homens medievais, posto que Agostinho de Hipona salientou através de seus discursos a concupiscência atrelada a carne.

Em suma, primeiramente encontramos uma conduta de ordem cívica, em que na Roma antiga do mundo pagão os deveres da cidade refletem no comportamento e na prática sexual do cidadão livre. Com os estoicos, posteriormente, compreendemos a vigência da prática do exame de si, em que o "eu" assume um lugar principal, não mais abrangendo uma ordem cívica. É apenas com a filosofia patrística que ocorre a elaboração dos impulsos sexuais como, quando fogem ao controle, resultado da consequência da desobediência original, surgindo uma luta constante entre os desejos e as verdadeiras necessidade da alma. Nesse sentido, os cristãos se submetem ao discurso religioso pautado no Pecado Original de Adão e Eva perante a lógica da obediência.

Além desse caráter não binário do interdiscurso, as práticas discursivas não são contínuas, uma vez que temos por exemplo a intolerância em relação à Homofilia ${ }^{35}$, na Roma antiga, assim como na Grécia dos primeiros séculos o sexo servia como meio de suporte para as iniciações ao conhecimento, estando vinculado com as formas de conhecimento da verdade. Passa-se ao caráter da descontinuidade quando na época imperial prevaleceu-se uma moral sexual que privilegiou o casamento apenas entre cônjuges de sexos opostos, valorizando ato sexual apenas no intuito da procriação. Ainda no Alto Império Romano, médicos e filósofos atuaram no sentido de promover uma moral sexual (BROWN, 1990, p. 79), que abraçada pelo Cristianismo, inaugurou uma nova época na Europa. Esse

\footnotetext{
${ }^{35}$ Ato sexual praticado entre dois homens na Grécia Antiga, quando não pertencentes ao mesmo estamento e o membro do estamento mais alto como o ativo da relação.
} 
novo imaginário constituiu-se por meio de um sistema de representações de cunho moral entre o homem e o seu corpo, promovendo um receio ao ato sexual e o amor entre rapazes, visto que a relação entre dois homens passou a ser proibida e taxada como sodomia ${ }^{36}$ na Idade Média.

No imaginário medieval, esse corpo doente era, então, considerado o sinal externo de algum pecado cometido pelos pais (por exemplo, relação sexual em períodos proibidos), resultado do castigo divino. Daí o fato corriqueiro de atribuírem-se desregramentos sexuais aos leprosos. Em virtude disso, os leprosos foram excluídos do convívio social e confinados em "gafárias" (designação ibérica) e obrigados a usar uma marca da infâmia: um guizo, uma matraca ou um sino quando circulassem pedindo esmolas (na França ocorreram massacres de leprosos em 1321. Mais uma vez, estabelecia-se a ligação entre corpo (doente) e pecado. (SANTOS, 2001, p. 16)

A prática do ato sexual, portanto, não é má, mas necessária quanto à reprodução e para perpetuação da palavra de Deus e deve ser vigiada, pois a satisfação da concupiscência da carne passou a ser retratada como a não vontade de Deus, tendo origem na queda posto que Adão perdeu o controle sobre os desejos.

Para Foucault, os primeiros autores cristãos teriam tomado de empréstimo princípios de uma moral pagã já preconizada por alguns filósofos e médicos na Antiguidade. Outrossim, o autor afirma que a moral cristã não passa de um fragmento da ética pagã introduzido no cristianismo, mas que propôs um novo modelo de concepção de si.6 Seria esse o período no qual emergiria uma concepção de família monogâmica, de comportamentos sexuais aceitáveis e de estrita fidelidade entre as pessoas casadas. O cristianismo trouxe novas técnicas para impor seus princípios morais e um conjunto de imperativos e proibições que determinariam as relações entre homem e mulher e o exercício da sexualidade. (SILVA, 2015, p. 42)

\footnotetext{
${ }^{36}$ Sodomia é a prática do coito anal seja entre dois homens ou entre um homem e uma mulher.
} 
Nessa perspectiva, inscreve-se no Cristianismo, juntamente de temas já presentes anteriormente ao seu apogeu, uma moral pautada na desobediência de Adão e Eva e na vigilância constante de si, em que a carne se fez "verbo".

Uma dupla evolução tende a fazer da carne a origem de todos os pecados e a deslocar o momento mais importante do ato em si para a inquietação do desejo, tão difícil de perceber e formular; pois que é um mal que atinge todo o homem sob as mais secretas formas. (FOUCAULT, 2014, p. 22)

Essa moral sexual de influência estoica emergirá uma conduta social interiorizada no imaginário medieval, em que surgirá uma vigilância interna e constante. Com o apogeu do Cristianismo e dos inúmeros discursos advindos de diversas comunidades cristãs, a carne adquire o tom da sexualidade, posto que "uma das primeiras novidades trazidas pelo Cristianismo foi o nexo entre a carne e o pecado.” (LE GOFF, 1994, p. 158). Essa carne passa a ser negativa no que tange a satisfação dos desejos e positiva no que concerne a reprodução dos homens para a perpetuação da palavra de Deus.

Assim, percebe-se aqui como a carne cristã estará marcada pela noção de desejo interior, que o sujeito não pode controlar, ou obedecer, implicando uma desobediência constante, fonte de toda impossibilidade de controle por si mesmo. Nesse sentido, a vigilância será mais do que necessária, será fundamental. Esse texto, ainda remete para o fato de que antes da queda, corpo de Adão e cada parte de seu corpo obedecia perfeitamente a alma e a sua vontade. Ele desconhecia a excitação voluntária. (CALÇADO, 2015, p. 159)

O desejo presente nos homens, segundo Agostinho, após o pecado necessita ser controlado e jamais saciado para que o corpo possa refletir a obediência à Deus, pois "o homem já não vive como quer. Julgar-se-ia feliz se vivesse como quer. Mas nem isso seria, se vivesse vergonhosamente." (CD, XIV, XXIV, tradução nossa) ${ }^{37}$.

No século XII, com a instituição do sacramento do matrimônio (segundo o modelo do Evangelho, monogâmico e indissolúvel), instalou-se um discurso eclesiástico normativo de controle das pulsões do corpo na sociedade dos laicos. Nessa linha de

\footnotetext{
${ }^{37}$ Ver no original: "Hinc evidentior miseria, qua homo non vivit ut vult. Nam si ut vellet viveret, beatum se putaret; sed nec sic tamen esset, si turpiter viveret." (CD, XIV, XXIV).
} 
pensamento, as relações sexuais só tinham alguma dignidade para a reprodução da espécie, o resto enquadrava-se no pecado carnal da luxúria. Assim, a Igreja imiscuía-se em questões da esfera do privado na Antiguidade e tornava-as da esfera pública, ou seja, da comunidade cristã por ela dirigida. (SANTOS, 2001, p. 15)

Nesse sentido, toda a culpa primária de Adão e Eva fora refletida nas ações dos homens. Esse desejo, segundo a doutrina do Cristianismo se faz presente inicialmente nos sujeitos por meio de um viés negativo, necessitado ser exteriorizado pela pastoral da confissão para que a busca pela verdade ocorra. É por intermédio do estimulo a confissão que a Igreja assegurou o controle sobre os sujeitos cristãos (MAGALHÃES, 2009, p. 188). É perante ao desejo sexual que se trava uma luta interna entre carne e espírito, apontando para um Cristianismo incumbido de reconhecer no indivíduo um sujeito portador de uma sexualidade perigosa e que possa o impedir de alcançar a salvação.

Vistos como os intérpretes da palavra sagrada e da verdade, os oratores consideravam que sua proximidade com o mundo divino os autorizava a controlar o resto da sociedade, procurando assim estabelecer normas que garantissem aos vivos a futura entrada no paraíso. (ZIERER, 2001, 117)

\section{Considerações finais}

O discurso, por assim entendermos, fornece controle e vigilância face a sociedade, na exclusão da permanência de um sujeito de conhecimento dado. Trava-se então, estratégias, perguntas, respostas de dominações, esquivas e lutas, como podemos exemplificar durante a Idade Média nas confissões como formas gerais de pesquisas sobre a verdade. Essa confissão que foi realizada pela Igreja cristã passou a confiscar tudo que se encontrava relacionado ao âmbito interpessoal, agindo como as formas de saber, pois o homem é pecador desde o seu nascimento segundo Tomás de Aquino e essa é uma característica advinda do Pecado Original (ST, I-II, q. 82, a. 1), ou seja, tem muito o que dizer.

Pela pastoral da confissão o pecador confessa todas as suas faltas perante a leis de Deus, tendo o confessor como função principal a guia do pecador para o caminho correto. Na confissão os homens passam a ter noção de suas vidas, atos e de suas almas nas 
formulas da doutrina cristão. É uma forma de controle social e das subjetividades humanas. Nesse sentido, o Ocidente medieval elabora sobre a prática da sexualidade a verdade do saber por meio de uma moral exteriorizada, em que na pastoral da confissão o homem tem o dever de falar sobre si para outrem, configurando-se em sujeitos subordinados pelos discursos disciplinadores de efeito verdade.

A Cristandade desde os seus primórdios fora negativa ao ato sexual. Fora a Igreja na Idade Média que, como força dominante na vida moral e espiritual dos homens, especificou o que seria permitido durante à prática do ato sexual (RICHARDS, 1993, p.33). Essa relação da Igreja com a moral sexual seguiu uma linha homogênea durante todo o período, pois já de início o sexo era visto como um mal necessário, uma vez que a perfeição espiritual transcende a carne, por meio da virgindade e do celibato e a "diabolização da carne e do corpo - considerado como suporte da devassidão e centro de produção do pecado negou ao corpo toda e qualquer dignidade.” (LE GOFF, 1994, p. 160). Nesse sentido, o casamento monogâmico e indissolúvel fora uma tentativa de regulamentação da atividade sexual, como vínculo de combate a fornicação, aceito apenas quando realizado para a procriação. É apenas no século IX, na França, que o casamento se torna doutrina sacramental, dado no que século XII a Igreja assume o total controle da instituição matrimonial. Nesse contexto, o papel da mulher continua subjugado, dentro e fora da instituição do casamento, pois o controle antes do pai passa para o marido. Essa mulher necessita ser disciplinada, visto que é considerada herdeira direta de Eva e que provoca no homem o despertar dos desejos mais profundos.

Sendo assim, por meio da centralidade cristã no período medieval "a visão da Igreja sobre o casamento como a pedra fundamental de sociedade cristã estável era geralmente aceita." (RICHARDS, 1993, p.44), assim como a visão sobre à prática ato e da moral sexual. Nesse sentido, a proibição ao ato quando praticado atingiu patamares cada vez maiores, chegando a ser proibido em dias de festas religiosas, domingos, durante os períodos de jejuns, na gravidez e o período menstrual da mulher.

Fora por meio das confissões e dos penitenciais que a Igreja pode deter algum conhecimento das práticas realizadas pelos leigos, uma vez que as penas mais graves eram direcionadas aos mais velhos, casados e principalmente aos clérigos, por serem 
representantes da ordem moral, ocorrendo por intermédio da negação da carne "o deslizamento do sentido da palavra caro - a humanidade assumida pelo Cristo na Encarnação - para o de carne fraca, corruptível, e do de carnal para o de sexual." (LE GOFF, 1994, p. 160). Consideramos, então, a Idade Média Central como um espaço de valor cultural, extremamente penetrado e regulado pelos valores religiosos e pela ideologia cristã.

\section{REFERÊNCIAS}

AGUSTINI SANCTI AURELLLI. De civitate dei. Vol. II, Lib. XIV-XXII. Liepzig: Lipsiae, 1987.

BÍBLIA DE JERUSALÉM. São Paulo: Paulus, 1994.

BROWN, Peter. Corpo e sociedade: o homem, a mulher e a renúncia sexual no início do Cristianismo. Rio de Janeiro: Jorge Zahar, 1990.

CALÇADO, Thiago. A carne se fez verbo: confissão cristã e sexualidade em Michel Foucault. 2015, 183f. Tese (Doutorado em Filosofia) - Faculdade de Filosofia. Pontífica Universidade Católica, São Paulo.

FEITOSA, Lourdes. Gênero e sexualidade no mundo romano: a antiguidade em nossos dias. História: Questões \& Debates. Curitiba, n. 48/49, p. 119-135, 2008.

FOUCAULT, Michel. Ética, sexualidade e política. Organização e seleção de textos: Manuel Barros da Motta. Tradução: Elisa Monteiro e Inês Autran Dourado Barbosa. Coleção Ditos e Escritos. v. V. 2 Ed. Rio de Janeiro. Forense Universitária, 2006.

FOUCAULT, Michel. História da sexualidade: a vontade do saber. São Paulo: Paz e Terra, 2014b.

LE GOFF, Jacques. O imaginário medieval. Lisboa: Editoral Estampa, 1994.

JARDIM, Rejane Barreto. A luxúria como herança de Adão. Revista do NIESC, Rio de Janeiro, Vol. 6, p. 120-128, 2006.

MAGALHÃES, Ana Paula Tavares. A heresia como forma de resistência à exclusão social: o caso dos Beguinos (sul da França e norte da Itália - 1307-1323). Revista Dimensões, Vitória, vol. 23, p. 182-198, 2009. 
RICHARDS, Jeffrey. Sexo, desvio e danação: as minorias na Idade Média. Rio de Janeiro: Jorge Zahar, 1993.

RANHEL, André Silva. História do corpo na Idade Média: representações, símbolos e cultura popular. Veredas da História, v. 11, n.1 p. 10-31, 2018.

SANTOS, Dulce Oliveira Amarante. O corpo dos pecados: As representações femininas nos reinos ibéricos (1250-1350). Textos de História, vol. 9, n 1/2, 13-30, 2001.

SILVA, Roberta Alexandrina da. Das comunidades a Roma: O feminino nas comunidades gnósticas e o processo de segregação sexual entre os porto-ortodoxos (séculos I-IV). Romanitas - Revista de Estudos Grecolatinos, Vitória, n. 6, p. 39-57, 2015.

TOMÁS DE AQUINO. Summa Theologiae. $2^{\circ}$ ed. Madrid: Biblioteca de Autores Cristianos, 2001.

VEYNE, Paul. "O Império Romano". In: ARIÈS, P. et DUBY, G. (org.) História da vida privada. V. I. Do Império romano ano mil. São Paulo: Companhia das Letras, 2009. 